\title{
A comparative study of ionothermal treatment of rice straw using triflate and acetate-based ionic liquids
}

\section{K.J. Jisha}

Indian Institute of Technology Madras

\section{Sunita Rajamani}

Indian Institute of Technology Madras

Dharmendra Singh

Indian Institute of Technology Madras

Gyanendra Sharma

Indian Institute of Technology Madras

Ramesh L. Gardas ( $\nabla$ gardas@iitm.ac.in )

Indian Institute of Technology Madras https://orcid.org/0000-0002-6185-5825

\section{Research Article}

Keywords: Lignocellulosic biomass, Pretreatment, Rice Straw, DBU based ionic liquid, lonothermal process, Morphological changes

Posted Date: November 29th, 2021

DOI: https://doi.org/10.21203/rs.3.rs-1005503/v2

License: (c) (1) This work is licensed under a Creative Commons Attribution 4.0 International License. Read Full License 
1 A comparative study of ionothermal treatment of rice straw using triflate 2 and acetate-based ionic liquids

K.J. Jisha., ${ }^{1,}$ Sunita Rajamani, ${ }^{1,2, \neq}$ Dharmendra Singh ${ }^{1,3}$, Gyanendra Sharma ${ }^{1,4}, \quad$ Ramesh L. 5 Gardas ${ }^{1, *}$

$6 \quad{ }^{1}$ Department of Chemistry, Indian Institute of Technology Madras, Chennai 600036, India

$7 \quad{ }^{2}$ Department of Chemistry, St. Joseph's College (Autonomous), Langford Road, Bengaluru 8 560027, Karnataka, India

$9{ }^{3}$ Department of Applied Science \& Humanities, Institute of Engineering \& Technology, Dr. 10 Ram Manohar Lohia Avadh University, Ayodhya, U. P. - 224001, India

$11{ }^{4}$ Faculty of Biological Science and Technology, Institute of Science and Engineering, 12 Kanazawa University, Kakuma-machi, Kanazawa, 920-1192, Japan

$13{ }^{\ddagger}$ These two authors have contributed equally to this work.

*Corresponding author: Tel.: +91 4422574248 fax: +91 4422574202 E-mail: gardas@iitm.ac.in

URL: http://www.iitm.ac.in/info/fac/gardas

\section{Abstract}

Ionic liquids (ILs) have found applications in the pretreatment of waste lignocellulosic biomass by interacting with the carbohydrate molecules present in the biomass materials. Pretreatment is essential before biomass conversion into valuable chemicals, fuels, and many other valueadded products. This comparative study mainly focused on the pretreatment ability of four ILs having acetate or triflate as a common anion with different cations. Among various studied ILs, diazabicyclo[5.4.0] undec-7-ene (DBU)-based acidic ionic liquid when used as a dual solvocatalyst showed significant structural modifications of the rice straw (RS) sample, through $\mathrm{C}_{6}-\mathrm{O}$ bond breakage assisted by the tertiary nitrogen in DBU cation. Structural modifications due to the pretreatment were confirmed through SEM, PXRD, and FTIR analysis. The elemental analysis confirmed that carbon content in original RS is reduced to $29 \%$ and $20 \%$ upon ionothermal treatment of RS with $\mathrm{IL}$ at $90{ }^{\circ} \mathrm{C}$ and $120{ }^{\circ} \mathrm{C}$, respectively. Additionally, TGA indicated that further pyrolysis could be easier with the pretreated rice straw yielding biochar up to $9 \%$ thereby reducing wastes. Conversion of RS was found to be $60 \%$ which reduced marginally to $50 \%$ after three cycles of recycling IL. The findings of this work provide the proof of concept that studied ILs with high thermal stability and recyclability 
1 should act as a potential solvocatalyst in sustainable pretreatment and other biomass 2 applications.

3

Keywords

Lignocellulosic biomass; Pretreatment; Rice Straw; DBU based ionic liquid: Ionothermal process; Morphological changes

\section{Introduction}

Bio-based chemicals and products, including biofuels, are the major targets by many agricultural biotechnologists. It is expected that nearly $27 \%$ of transportation fuels can be replaced with biofuels by 2050 [1]. Implementing the biorefinery concept wholly depends on biomass as a valuable feedstock for producing bio-based fuels, cosmetics, chemicals, textiles, etc. [2]. Pyrolysis of lignocellulose, in which the feed substance is cracked thermally in the absence of oxygen, is used to crack lignocellulosic materials [3]. Pyrolysis produces a solid (also called char or biochar), liquid (also called bio-oils), and gas products (both condensable and non-condensable). Different factors, including the addition of catalysts, temperature, and type of lignocellulose/biomass, water content, inherent minerals, heating rates, residence time, pressure, environment, and reactor patterns, contribute to this conversion process. Henceforth, one can select the products needed through pyrolysis by adjusting the parameters. Among these methods, catalytic pyrolysis has gotten the maximum attention in the last few years [3,4] In this regard, thermogravimetric analysis (TGA) is becoming an imperative tool for judging the pyrolysis of the treated biomass apart from other morphological studies[5,6].

The estimated global production of these lignocelluloses amounts to 200 billion tons, thereby proving suitable candidates for sustainable development [7]. Lignocellulosic biomass can be food as well as non-food. The non-food crop residues include removable materials left after harvesting primary crops like corn, wheat, or rice straw. These are widely available, and this waste is either burnt or disposed of each year to avoid the chances of any diseases in the coming year's crop. However, this leads to one of the major causes of pollution of the year's air quality. Hence to avoid this step that affects the air quality, these waste straws can be used for various purposes, and one among them could be to convert into new bio-based materials or biofuels, or any other valuable chemicals. Treating the biomass with various chemicals, considering the complicated plant cell wall, converting waste biomass materials into useful value-added products, etc. has been worked out by many researchers $[8,9]$ 
Rice straw (RS) or lignocellulose is a polymer of cellulose, hemicellulose, and lignin in which the most resistant part of rice straw is lignin that serves as the "glue" by binding the cellulose and hemicellulose or rather skeleton of plants that gives both rigidity and support to the lignocellulosic structure. There are several studies on rice straw and its waste management like using them for fibreboards and organic fertilizers [10-12]. The aromatic chemical structure imparts a high calorific value to the lignin molecule, valuable for other chemical conversions. The presence of lignin hinders carbohydrate molecules from reacting to acids or bases, and thus most of the carbon bonds are not broken to give out valuable chemicals [13]. The efficient valorization of biopolymers depends mainly on the pretreatment, which is necessary for the biomass sample's structural modifications.

Pretreatment, the high energy demanding process, becomes something inevitable because it adjusts the structural characteristics of lignocellulose, and the structural alterations are highly connected to the mode of the pre-treatment method chosen [14-17]. The recalcitrance of the biomass material obstructs the polysaccharide accessibility; hence, various pretreatment techniques including physical, chemical, and biological methods were evolved. Negative aspects of a few pretreatment techniques were the high energy requirement and the production of unwanted by-products. A handful of reviews are available depicting the pros and cons of each category of techniques [18]. Moreover, the combination of multiple factors like substrate composition, pretreatment type, dosage, and efficiency of enzymes being used for hydrolysis impacts the digestibility of the lignocellulosic biomass used. Application of selective and benign solvents for biomass pretreatment would be preferable, and thus ionic liquids (ILs) were introduced in this field as effective pretreatment solvents $[19,20]$

ILs comprise a weakly linked asymmetric cation (organic/inorganic) and anion (organic) in their structure with a melting point lesser than room temperature [21-23]. The scientific community was constantly looking for this kind of solvent where the properties could be tuned according to the desired task. They are widely known as designer solvents owing to the possibility of designing the ionic liquid structure with suitable properties [24,25]. They are well known and are widely used in various fields such as catalysis, electrochemistry, pharmacology, separation, and purification of biomolecules, extraction, etc. [26]. The fascinating properties of ILs are many in which higher thermal as well as chemical stabilities, non-flammability, negligible vapor pressure are quite a few to be listed [27,28]. Studies have shown that ILs can be used to dissolve bagasse, corn stalks, wheat, wood, etc., and this process is called ionothermal treatment in which ILs have acted as a dual solvocatalyst [29,30]. ILs fall into the 
1 Hydrogen bond basicity of anions present in IL play a key role in cellulose dissolution and acetate [31] chloride [32], [33] carboxylates [34,35] etc. come in the front line in this category. 1-butyl-3-methylimidazolium chloride ([Bmim][Cl]) is mainly used for rice husk dissolution and conversion [36]. However, this study used an additional amount of inorganic acid to meet the pretreatment requirement. Recently, Badbedast and coworkers from Iran have conducted a detailed study on rice straw pretreatment using an acidic IL namely1-(carboxymethyl) pyridinium chloride with acetate and chloride groups present in the structure. Various analyses, including FT-IT, XRD, and SEM, revealed the restructuring and increased free volume between cellulose chains in the rice straw sample [37]. Cholinium ILs with amino acid-based anions were reported for selective delignification of lignocelluloses and found that the pretreated samples were exhibiting higher saccharification rate as well as higher polysaccharide digestibility [38]. In another study, biomass pretreatment with IL was coupled with membrane filtration. FT-IR, XRD, SEM and Zeta potential assessments were used to explain the role of ILs in lignocellulose dissolution and the ability of different imidazolium ILs in regenerating the cellulose [39]. New generation of ILs, called deep eutectic systems (DES) was also reported for the biomass pretreatment and found to be promising pretreatment solvents for future biorefineries [40,41].

In this study, we have discussed the comparative pretreatment efficiency of four different ILs having triflate and acetate-based anion. The acetate-based ILs were used due to the reported studies which showed effective pretreatments for rice straw and other lignocellulosic materials [42] whereas the reason behind choosing a triflate-based ILs was its better thermal stability. On the selection of cation, the triazole-based IL was found to be high polar than organic solvents [21] whereas DBU was spectated better air, water, and thermal stability, also the Lewis basic property of its tertiary nitrogen which was capable of breaking the H-bonds between the cellulose molecules thereby forming new H-bonding between the IL and the cellulose [43]. In addition to that, DBU-based ILs are considered as having higher $\beta$ values (between 0.8 to 0.9 ) and again high $\pi *$ values (0.9) [44] which are found to be similar to the value of DMSO [45]. The high values of $\beta$ and $\pi^{*}$ are probably suggestions of van der Waals attractions and weak hydrogen bonds. According to molecular simulation studies, the cations of ILs are seen to be above and below the planes of the glucose ring. This effect is being explained by an anisotropic molecular surface of the straight cellulose strands having a smaller hydrogen bonding periphery [46]. 
1 Harsh conditions including high temperature, acidic and alkaline conditions, etc. make 2 cellulose significantly soluble in particular solvents [47] whereas ILs don't demand such higher conditions to an extent. The use of high temperature accelerates the dissolution and degradation leading to lesser yields for regenerated cellulose [29]. This kind of IL treatment has further advantages such as the pretreatment uses lower temperatures, less hazardous process and corrosion is not always a concern when the right choice is made with the combination of cation and anion of the IL and finally the regeneration of the IL makes the process feasible and economical. Additionally, ILs can be recycled and reused by taking into consideration the economic aspects [48]. The pretreatment is intended to reduce the energy required for the rice straw's chemical modification, limiting hydrogen bonding and decreasing the degree of polymerization, thereby decreasing the crystallinity. One of the approaches was an IL pretreatment process followed by enzymatic hydrolysis, which has proven that some ILs do not deactivate enzymes ever [49]. Fundamental studies regarding pretreatment are getting attention over basic research aspects, however, the attempts to bring in industrial-level applications are restricted owing to the cost issues related to some ILs.

\section{Experimental Section}

\section{Materials and Methods}

(i) Synthesis of ILs

The synthesis of studied ILs having triflate anion i.e. ([DBUH][OTf]); [BtTzm][OTf] was reported in our previous report [50,51]. In brief, the synthetic scheme (Scheme S1 and S2) and characterization through ${ }^{1} \mathrm{H}-\mathrm{NMR}$ and ${ }^{13} \mathrm{C}-\mathrm{NMR}$ was presented in supporting information (Fig. S1 and S2). Further for assessing the comparative studies, acetate-based ILs were developed with dimethyl ethanol ammonium (DMEA) and diethyl ethanol ammonium (DEEA) cations. The synthetic procedure and its structural characterization of [DMEA][OAc] and [DEEA][OAc] were shown in Scheme S3 and Fig. S3, S4 respectively [22,52].

\section{(ii) Rice Straw Sample Preparation}

Rice straw was collected from the fields of Ayodhya, Uttar Pradesh, India. It was stored at $20-30{ }^{\circ} \mathrm{C}$ in dark followed by washing with water and acetone, after which it was then dried in the oven at $70{ }^{\circ} \mathrm{C}$ for overnight. 
2 The detailed procedures of pretreatment are presented in the supporting information file (Fig. 3 S5). Briefly, the original rice straw (fig. S5 a) was added to the DBU-based IL (fig. S5 b). The 4 original rice straw was characterized by using SEM and PXRD. A total of 20:1 ratio of IL: rice 5 straw was added and stirred for $6 \mathrm{~h}$ at $90{ }^{\circ} \mathrm{C}$. The anti-solvent was added when the mixture of $6 \mathrm{IL}$ and the rice straw was at room temperature and then it was filtered. The IL along with water 7 formed the filtrate (fig. S5 c) and the undissolved part formed the residue (fig. S5 d).

(iv) SEM and PXRD Studies

The obtained residue was characterized using powder X-ray diffraction (PXRD) and scanning electron microscope (SEM) to study the changes that occurred post-dissolution. The morphology of the untreated RS, as well as the treated RS, was determined using SEM (Quanta 450, FEI, USA). The solid samples were fixed on carbon tapes on sample stubs and were imaged in low vacuum mode. Images were acquired with a $30 \mathrm{kV}$ acceleration voltage. PXRD patterns were recorded in the reflection mode using Brucker D8 Advance in the $2 \Theta$ range 5$50^{\circ}$ with a step size of $0.03^{\circ}$ and a step time of $1 \mathrm{~s}$ at $40 \mathrm{kV}$ and $30 \mathrm{~mA}$ at room temperature.

(v) FTIR

FTIR JASCO was used for determining the functional groups in the biomass molecules and the scanning was carried out between the wavelength ranges of 4000-400 $\mathrm{nm}$. $\mathrm{KBr}$ (ratio 1:100) powder pellets were prepared to measure on a Nicolet5700 Fourier transform infrared (FT-IR) spectrophotometer Co., USA) in the spectral range of 400 to $4000 \mathrm{~cm}^{-1}$. A resolution of $4 \mathrm{~cm}^{-1}$ with 124 scans was carried out.

(vi) CHN Analysis

The elemental analysis (CHN) was carried out using a CHNS/O Analyzer (Perkin Elmer instruments, Series II, 2400) where the measurement time was 8-10 minutes. TGA was recorded using TA Instruments model Q500 Hi-Res TGA. The temperature scan rate is 20 ${ }^{\circ} \mathrm{C} / \mathrm{min}$ in a nitrogen atmosphere, and the flow rate was $60 \mathrm{~mL} / \mathrm{min}$ and was studied between 60 and $900{ }^{\circ} \mathrm{C}$. 


\section{$1 \quad 3 . \quad$ Results and Discussion}

Herein, the four ILs namely [DBU][OTf], [BtTzm][OTf], [DMEA][OAc] and [DEEA][OAc]were used as a dual solvocatalyst in a 20:1 ratio of IL: RS. Structures of the different ILs used here in this study are shown in Fig. 1. A similar type of pretreatment study was already done where the biomass to solvent ratio was maintained to be 1:10 g/g. In such a study the solvent was used as a binary mixture of [TEA][HSO 4$]$ : water with $4: 1 \mathrm{w} / \mathrm{w}$ ratio and they have conducted the experiments in triplicate at $120^{\circ} \mathrm{C}$ for $24 \mathrm{hrs}$ [53]. The acidic character of the ILs served to be useful for its dissolution and its larger amount helped for its behavior as a solvent.<smiles>C1CCC2=[NH+]CCCN2CC1</smiles><smiles>O=S(=O)([O-])C(F)(F)F</smiles>

[DBU][OTf]<smiles>C[NH+](C)CCO</smiles>

[DME][OAc]<smiles></smiles><smiles>O=S(=O)([O-])C(F)(F)F</smiles>

[BtTzm][OTf]<smiles>CC[NH+](CC)CCO</smiles><smiles>CC(=O)[O-]</smiles>

[DEE][OAc]

13 Figure 1. Diagram representing the structure of four ionic liquids used in this study. Where, $14[\mathrm{DBU}][\mathrm{OTf}]=1,8$-Diazabicyclo[5.4.0]undec-7-en-ium triflate, [BtTzm][OTf] = Butyl triazolium triflate, $[\mathrm{DME}][\mathrm{OAc}]=$ Dimethyl ammonium acetate, and $[\mathrm{DEE}][\mathrm{OAc}]=$ Diethylethanolamine acetate.

Moreover, scanning electron microscopy (SEM) is an imperative tool for examining the morphological aspects of biomass. The surface of the untreated RS was found to be well organized due to the lignin; which acts as a skeleton where we can see a well-organized ribcage-like structure or binding agent to hemicellulose and cellulose (shown in Fig. 2a and 2 b). 
1 started appearing in the $90{ }^{\circ} \mathrm{C}$ and $120^{\circ} \mathrm{C}$ ionothermal treatment due to the thermo-mechanical 2 force applied besides the acidic media. The ionothermal treatment at $140{ }^{\circ} \mathrm{C} \mathrm{RS}$ was observed 3 to the similar to untreated RS, which shows the worst effect on the structural change. This 4 could be mainly attributed due to the degradation of the IL as it turned black instantly. Further, this degradation was confirmed through the NMR of the extracted IL via post-ionothermal treatment, which is entirely different from the original NMR of [DBU][OTf].

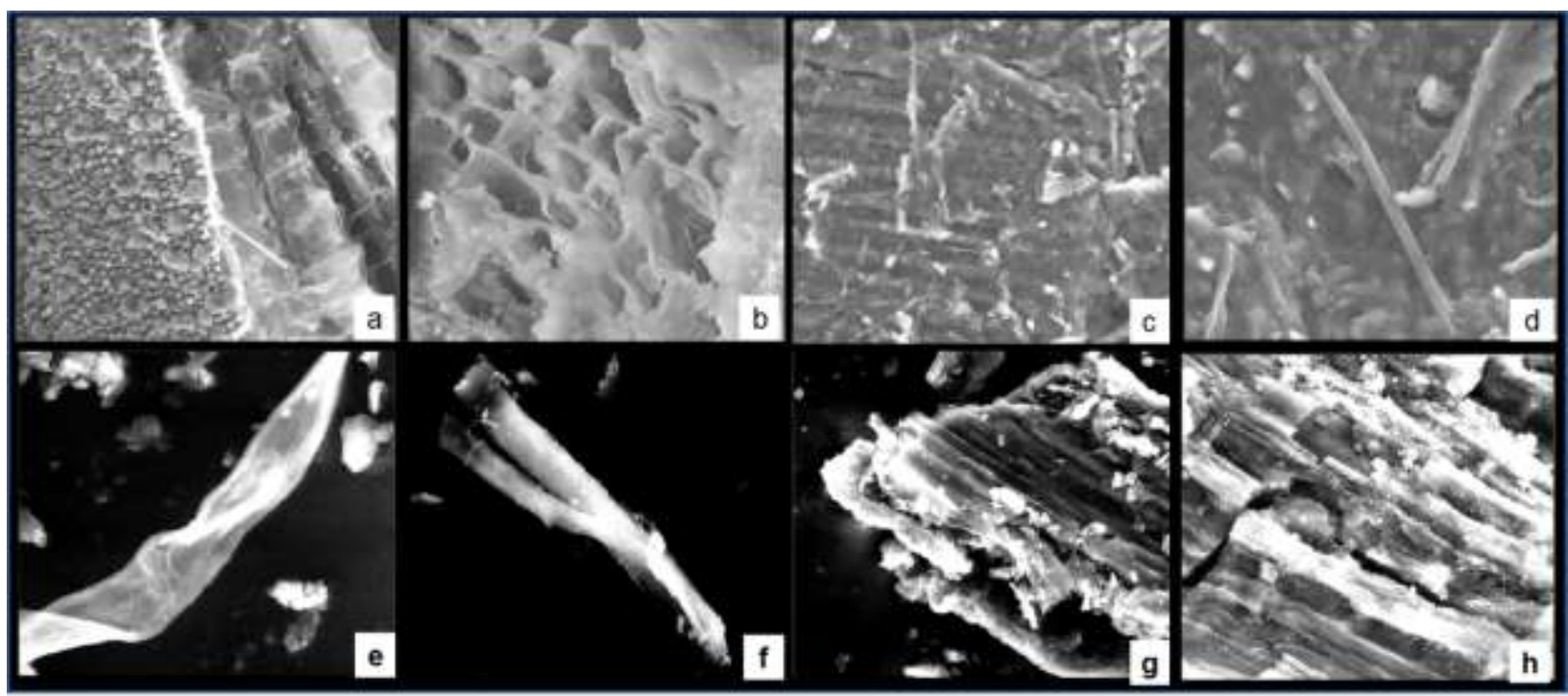

9 Figure 2. a) Outer and the cross-sectional organized surface of the original rice straw before treatment at $100 \mu \mathrm{m} ; \mathbf{b})$ cross-sectional view of original rice straw before treatment at $50 \mu \mathrm{m}$; Rice straw after pretreatment with [DBU][OTf] at different temperatures are viewed at different sizes are shown in figures (c) - (h) where c) $90{ }^{\circ} \mathrm{C}$ at $100 \mu \mathrm{m}$; d) $90{ }^{\circ} \mathrm{C}$ at $50 \mu \mathrm{m}$; e) $120{ }^{\circ} \mathrm{C}$ at $100 \mu \mathrm{m} ;$ f) $120^{\circ} \mathrm{C}$ at $\left.50 \mu \mathrm{m} ; \mathrm{g}\right) 140{ }^{\circ} \mathrm{C}$ at $100 \mu \mathrm{m}$ and $\left.\mathbf{h}\right) 140{ }^{\circ} \mathrm{C}$ at $50 \mu \mathrm{m}$.

Further, to examine the effect of ionic liquids having the same anion on pretreatment of RS we have carried out similar studies using ([BtTzm][OTf]) IL. Fig. 3a-d represent the morphology of RS after pretreated with [BtTzm][OTf] at a lower temperature $90^{\circ} \mathrm{C}$. In the presence of triazolium cation, only a few fibers were formed in the diameter range of 4.5 to 5.2 $\mu \mathrm{m}$. Thus, the fibers were not completely released when triazolium cation was used for pretreatment. Here, a lot of fibers were visible in case however those fibers were still bound to each other. Moreover, two more ILs were compared having a common anion as acetate and their cation was varied. However, [DMEA $][\mathrm{OAc}]$ and [DEEA][OAc] showed eroded surfaces, and the formation of fewer fibers was observed only in the case of DEEA (Fig. 3 e-h). Overall, observed SEM data suggest that complete disorganization of the lignocellulosic material when 
1 [DBU][OTf] whereas in the case of the other three studied ILs we did not see any proper reorganization. Since DBU-based IL has proved a better result among other studied ILs, we went ahead to characterize other properties of the pretreated product obtained through [DBU][OTf].

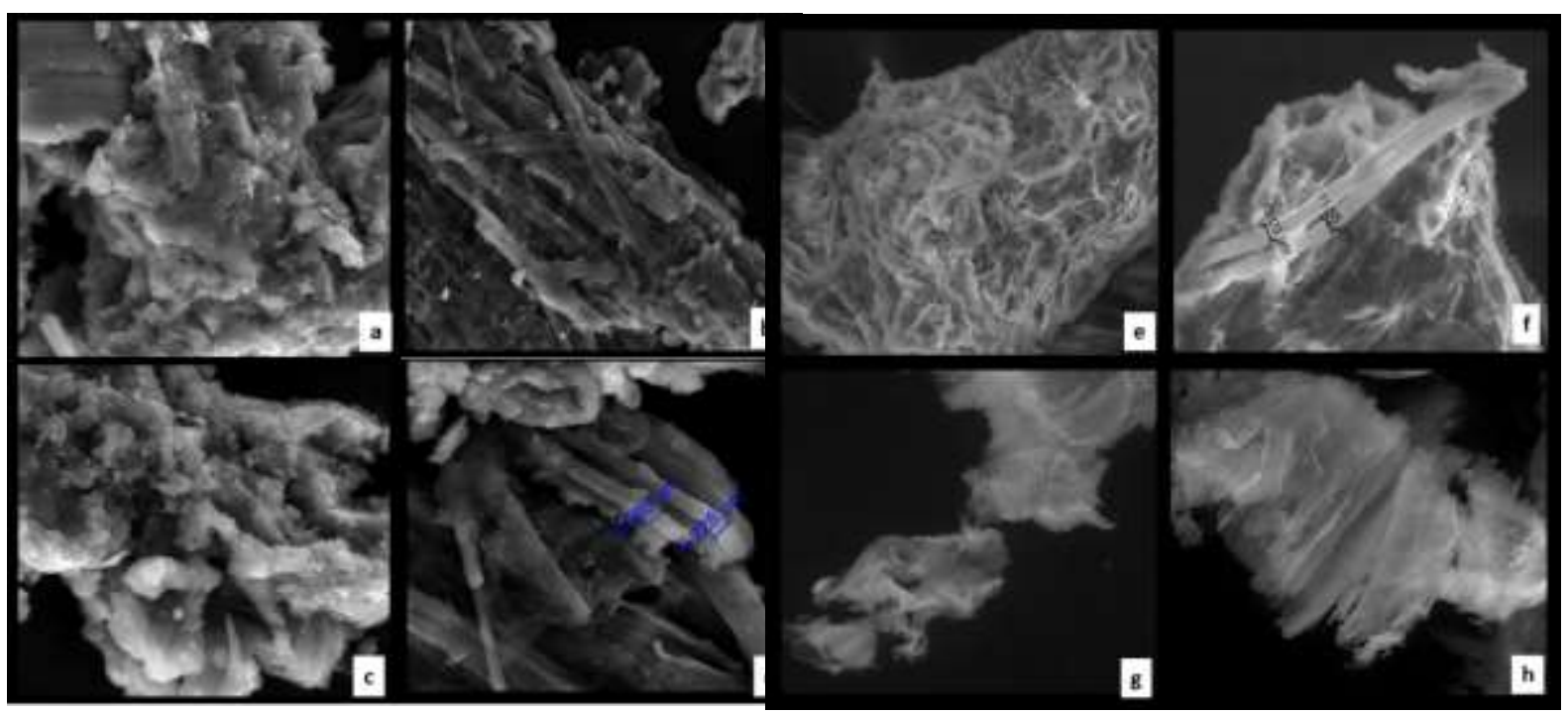

Figure 3: SEM image for rice straw post-treatment with [BtTzm][OTf]-based IL a,b) at 100 $\mu \mathrm{m}$ and (e,d) at $50 \mu \mathrm{m}$. e,f) at 100 and 50 for [DME][OAc] and $\mathbf{g , h}$ ) at 100 and 50 for [DEE][OAc]

PXRD patterns are useful in the study of the crystalline behavior of a material and to relate the characteristics of the samples with the crystal structure. All of the lignocellulosic biomass samples are complex molecules with partial crystalline and partial amorphous nature but the crystallinity would differ from one sample to the other one. The crystalline portion would be the indication of cellulose chains closely held together with the H-bonding whereas the amorphous regions suggest the disordered region with no $\mathrm{H}$-bonding is present. Ionic liquid pretreatment strongly affected the crystallinity of the biomass samples and is compared with the same for the untreated RS sample. Moreover, the pretreatment with IL at two different temperatures indicated the possibility of a decrease in the peak intensities as the reaction temperature increased [54]. The PXRD patterns for the rice straw samples with and without IL pretreatment is shown in the fig. 4 where the crystalline peaks are decreasing after the pretreatment in comparison to the pure RS.

Several studies have reported the Segal method, however, there are many debates about the same, and new methods have evolved [55], [56]. Our group carried out deconvolution using 
1 Fityk software [57]. Commonly used functions for deconvolution of the diffraction patterns are 2 Gaussian, Lorentzian, and pseudoVoigt (mixtures of Gaussian \& Lorentzian). But we used both 3 Gaussian and pseudoVoigt and compared the calculations of the $\mathrm{CrI}$ and the crystallite size. 4 French suggested that Gaussian peaks were not enough to satisfy the amorphous peaks alone. 5 Hence, pseudoVoigt was also taken into consideration.

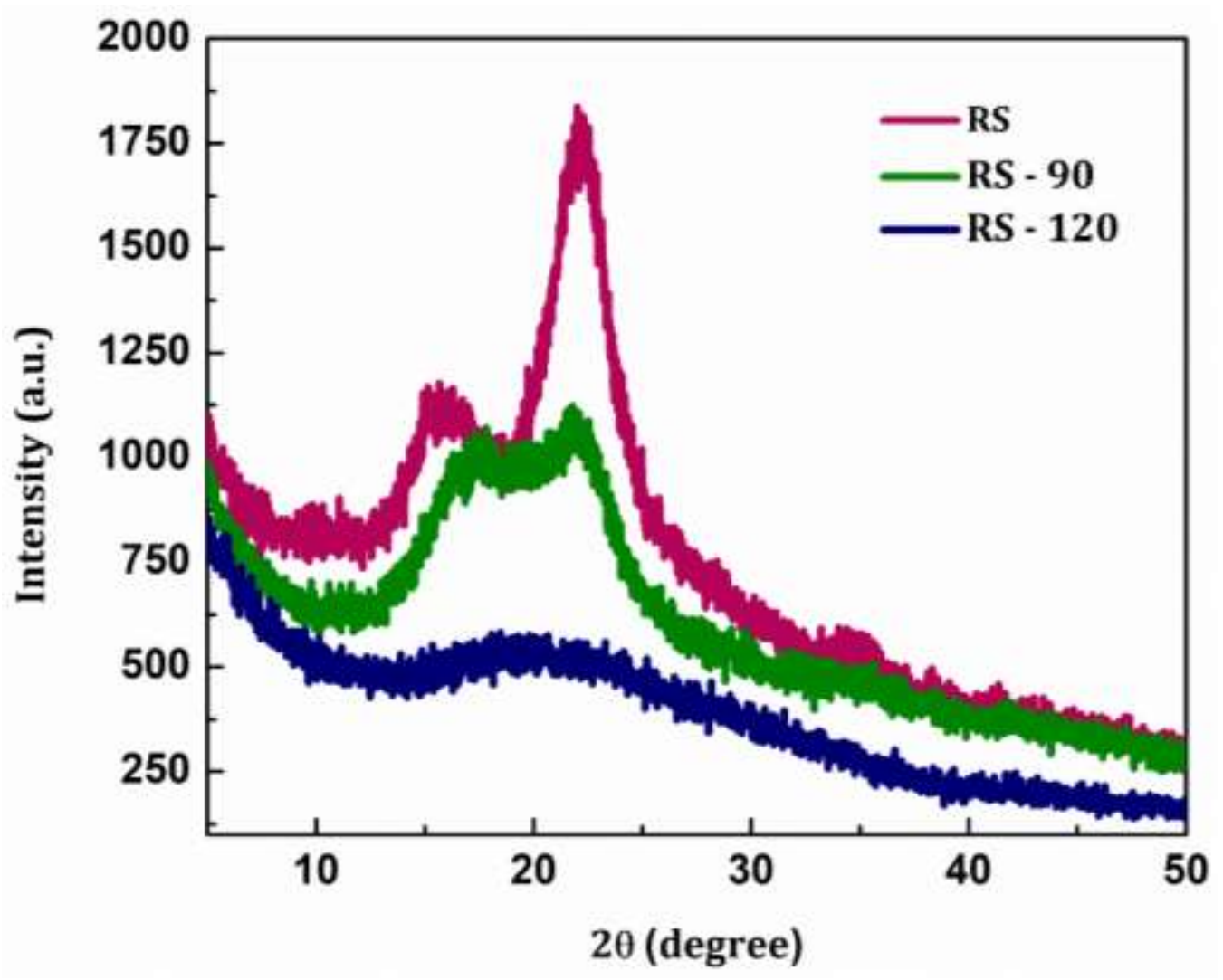

Figure 4. PXRD patterns for original rice straw and the residue obtained post-treatment using [DBUH] [OTf] (RS: Original Rice Straw, RS - 90: Rice Straw after heating at $90{ }^{\circ} \mathrm{C}, \mathbf{R S}$ 120: Rice Straw after heating at $120^{\circ} \mathrm{C}$ )

Yao et al 2020 reported background subtraction in the case of PXRD data where the background must be removed before plotting the PXRD data for the experiments. The background error might originate from the air scattering, thermal agitation of atoms, and sample holder. The background was subtracted before peak deconvolution which ensured a stable baseline fitting thereby helping in reducing error [58].

Fityks Levenberg-Marquardt algorithm was used to run the fittings. The crystallite sizes (L) for the main 200 peak, using full-width half maximum (FWHM) values were calculated using the Scherrer equation, which is shown in equation 1. 
$2 \quad L=\frac{K \lambda}{(\beta \cos \theta)}$

$\lambda=1.54 \mathrm{~A}^{\circ}$ (since Copper-K $\alpha$ was the target)

The k value was taken as 0.94 as suggested by Rico et al [59] and the other parameters were calculated as shown in supplementary information (Table S1). The crystallinity index (CrI) of the rice straw samples before and after the pretreatment with the IL was calculated using the following equation.

$\operatorname{CrI}=100 \times\left({ }^{A_{\text {cryst }}} / A_{\text {Tot }}\right)$

$\mathbf{A}_{\text {crsyt }}=$ area of crystalline peak in this case the peak at 200 plane

$\mathbf{A}_{\text {Tot }}=$ area of total peaks

Table 1: Crystallite size and crystallinity index using Gaussian and pseudoVoigt fitting

\begin{tabular}{|l|l|l|l|l|}
\hline Samples & \multicolumn{2}{|l|}{ Gaussian } & pseudoVoigt \\
\cline { 2 - 5 } & $\begin{array}{l}\text { Crystallite } \\
\text { size (nm) }\end{array}$ & CrI \% & $\begin{array}{l}\text { Crystallite } \\
\text { size (nm) }\end{array}$ & CrI \% \\
\hline Pure RS & 3.20 & $46.34 \%$ & 2.41 & $36.00 \%$ \\
\hline RS 90 & 2.16 & $46.22 \%$ & 2.01 & $33.44 \%$ \\
\hline RS 120 & 0.56 & - & 0.56 & - \\
\hline
\end{tabular}

This decrease in crystallite size after pretreatment could be explained as the periodicity in the lattice decreases, and hence the disorder in the lattice increases. In our study, the area of the peak with $22^{\circ}$ was taken. The reason to consider this peak was that this had the maximum intensity in all the cases. Rest all peaks, including the peak at $22^{\circ}$ were considered in the summation of the total peaks to calculate the CrI. The SEM results were further supported by the PXRD results, indicating that the change in the crystallinity and tearing up of the lignocellulose to fibers occurred when ionothermal treatment at 90 and $120{ }^{\circ} \mathrm{C}$ was provided.

The decrease in the crystallinity can be because of two reasons: first, removal or conversion of lignin, and second, removal or conversion of cellulose to some furans such as 
1 possibility as the temperature was lower than $300{ }^{\circ} \mathrm{C}$. The glycosidic bonds linking the glucose 2 units in cellulose are not very strong. There are inter and intramolecular hydrogen bonds 3 associated per glucosyl unit in raw cellulose. The packing of numerous cellulose flat sheets is 4 mainly through van der Waals forces and H-bonding. (Scheme 1). However, the weak 5 glycosidic bonds in cellulose cleave under acid or high-temperature conditions. The latter was 6 proven due to the qualitative analysis of 5-hydroxymethylfurfural (HMF) using TLC sheets in 7 the IL part post-filtration (Scheme 1).

8

9

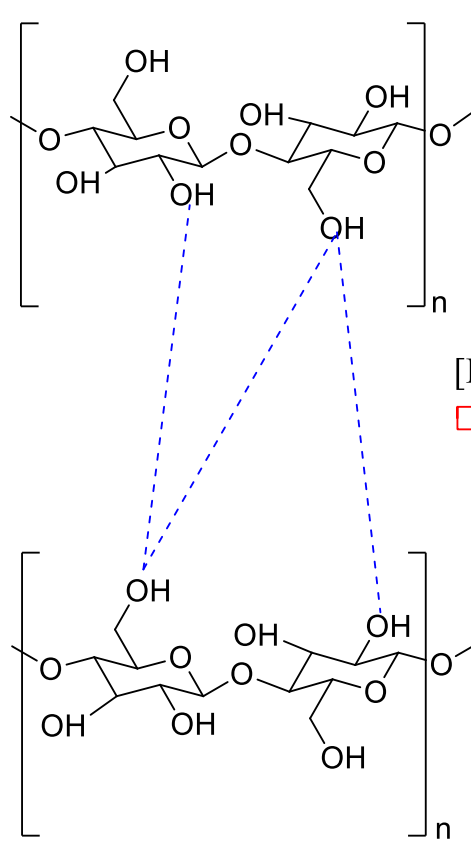

Inter sheet H-bonding in cellulose

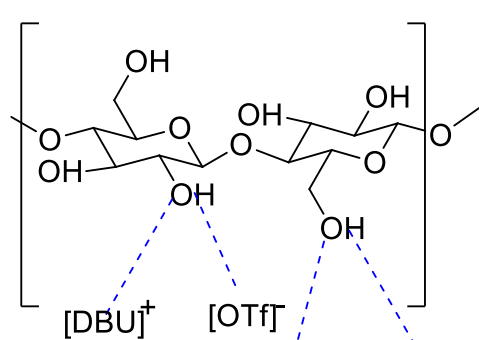
$\mathrm{DDBU}^{+}$[OTf $^{-}$

$[\mathrm{DBU}][\mathrm{OTf}]$
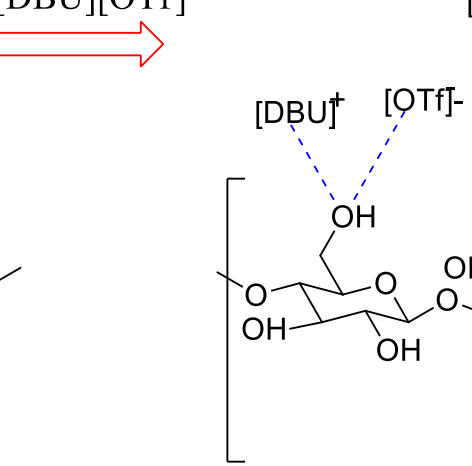

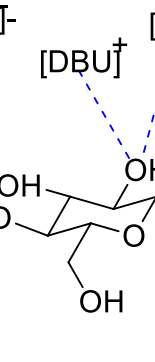

Breakdown of cellulose inter-sheet $\mathrm{H}$ bonding and formation of new $\mathrm{H}$-bonding between cellulose and ionic liquid. Lower crystaline cellulose in ionic liquid and dehydration of cellulose to give glucose by breaking the glycosidic bond 

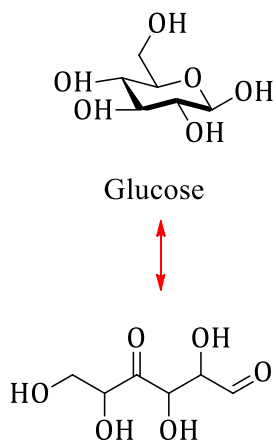

2,3,5,6-tetrahydroxy - 4-oxohexanal<smiles>[Te][Te]</smiles><smiles>O=C(CO)C(O)C(O)C(O)CO</smiles>

1,3,4,5,6-pentahydroxy -hexan-2-one

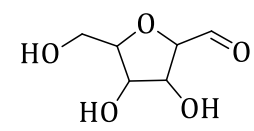

3,4-dihydroxy-5-(hydroxymethyl) tetrahydrofuran-2-carbaldehyde

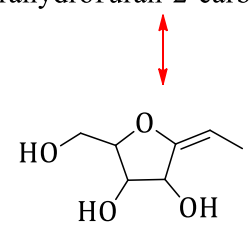

(E)-2-ethylidene-5-(hydroxymethyl) tetrahydrofuran-3,4-diol
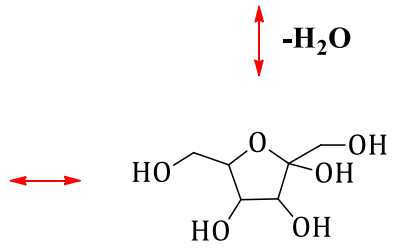

2,5-bis(hydroxymethyl)tetrahydro -furan-2,3,4-triol

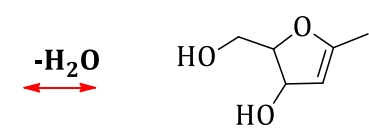

4-hydroxy-5-(hydroxymethyl)4,5-dihydrofuran-2-carbaldehyde
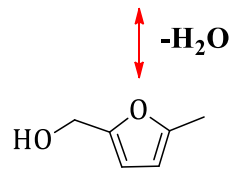

Hexamethylfurfural

3 Scheme 1: Mechanism of cellulose interacting with IL (adapted and modified from [60], [61], and [62]. The blue dots indicate H-bonding.

This decrease in crystallinity made it more porous than before, and hence further treatments like enzymatic hydrolysis can be carried out more effectively. The effectiveness was tested by the pyrolysis method mentioned in the last section. The high temperature would have removed the volatile components, and due to these two factors, the morphological structures differed before and after treatment as also agreed with SEM images (Fig. 2).

Moreover, the Interaction of $-\mathrm{OH}$ groups present in cellulose with both cation and anion of ILs make it soluble in those solvents. Oxygen atoms that belong to the $-\mathrm{OH}$ groups of cellulose function as electron donors and hydrogen atoms serve as electron acceptors. IL anions also behave as electron donors. Cations having an electron-rich aromatic $\pi$ system is not interacting much with hydroxyl oxygen atoms through either nonbonding electrons or $\pi$ electrons whereas anions prefer to interact through hydrogen bonding to the hydroxyl proton of cellulose moiety [63].

Such interactions were mainly investigated through the FTIR analysis. Thus it was carried out for the RS as well as ionothermally treated RS at three different temperatures as shown in Fig. 4. The -OH stretching at 2945 from original RS disappeared in the $90{ }^{\circ} \mathrm{C}$ and $120{ }^{\circ} \mathrm{C}$ indicating cleavage of some $\mathrm{H}$-bonds (mainly $\mathrm{O}(6) \mathrm{H}----\mathrm{O}(3)$ ) during the process of 
1 conversion of cellulose to $\mathrm{HMF}$ via glucose. At $140{ }^{\circ} \mathrm{C}$, charring has occurred so the product was not analyzed. In addition, FTIR was carried out for the original RS as well treated RS at 90, 120, and $140{ }^{\circ} \mathrm{C}$. The FTIR at $140{ }^{\circ} \mathrm{C}$ also confirmed that IL degraded at this temperature and so there was hardly any change in the RS's composition besides the charring and color of IL turning to black. Treated RS at $140{ }^{\circ} \mathrm{C}$ was also used to measure the IR data and no modification was observed in its peak because their chemical constituent looks quite similar to the untreated one. The FTIR confirmed the removal of some lignin and cellulose H-bonding when the RS was treated at $120{ }^{\circ} \mathrm{C}$. Visible changes were observed in the texture and composition of the RS after the dissolution in IL for $6 \mathrm{~h}$. These conversions for the recycled ILs were obtained by calculation of mass before and after the treatment.

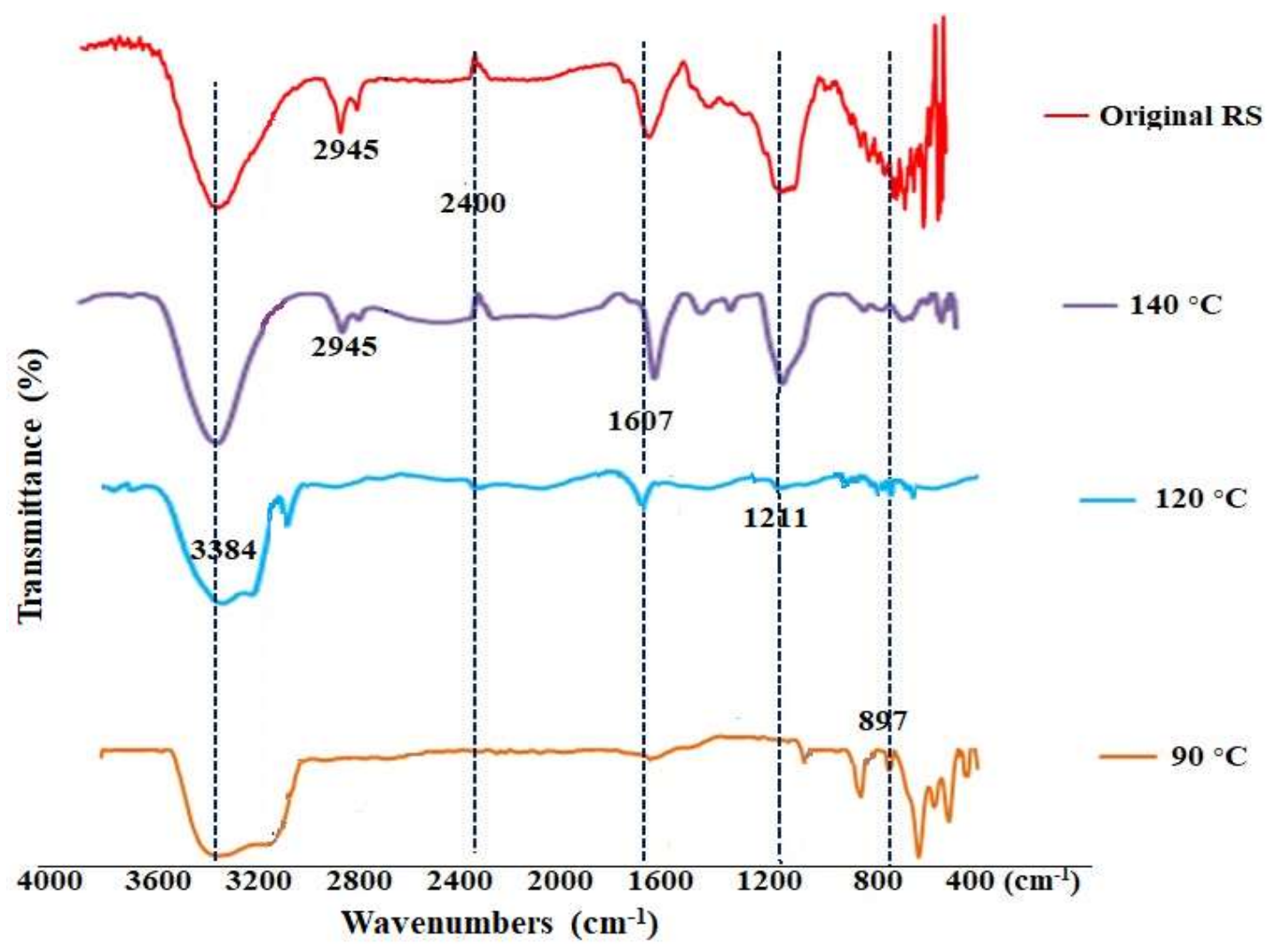

Figure. 4: Comparative FT-IR studies on original rice straw (RS) and RS at three different temperatures $\left(90,120\right.$, and $\left.140{ }^{\circ} \mathrm{C}\right)$

Next, the band at $3383 \mathrm{~cm}^{-1}$ specifies the $\mathrm{C}-\mathrm{H}$ and $\mathrm{O}-\mathrm{H}$ stretching band of cellulose which broadens on treatment at $90{ }^{\circ} \mathrm{C}$ and $120^{\circ} \mathrm{C}$. O-H stretching is obtained more in the case where the treatment occurred at $120{ }^{\circ} \mathrm{C}$. The peak at $2945 \mathrm{~cm}^{-1}$ corresponded to the $\mathrm{O}-\mathrm{H}$ and $\mathrm{C}-\mathrm{H}$ stretching band of the lignocellulosic matrix, and this was not present in the RS treated at 90 
1 and $2847 \mathrm{~cm}^{-1}$ ) which disappeared at $90{ }^{\circ} \mathrm{C}$ and $120^{\circ} \mathrm{C}$ treated RS. The peak around $1607 \mathrm{~cm}^{-}$

$2{ }^{1}$ corresponded to lignin bonds which also disappeared in lower temperature treatments. The

3 peak at $1211 \mathrm{~cm}^{-1}$ corresponds to the syringyl ring and $\mathrm{C}-\mathrm{O}$ stretching lignin character

4 vibration. The peaks between 1000 and $400 \mathrm{~cm}^{-1}$ corresponded to the presence of silica bonds

5 in the lignocellulose. The treatment at $120^{\circ} \mathrm{C}$ showed deformation in the silica bonds as the

6 peaks did not appear. Barriers to the RS towards enzyme accessibility were removed after

7 ionothermal treatment, and the cellulose and some hemicellulose portion were exposed.

8 Additionally, the decrement of the extent of lignin has been monitored through TGA

9 analysis, where we can see that removal of cellulose and lignin and that was the reason lesser

10 biochar were obtained in these cases. TGA data supported that the pyrolysis temperature 11 decreased for the pretreated RS.

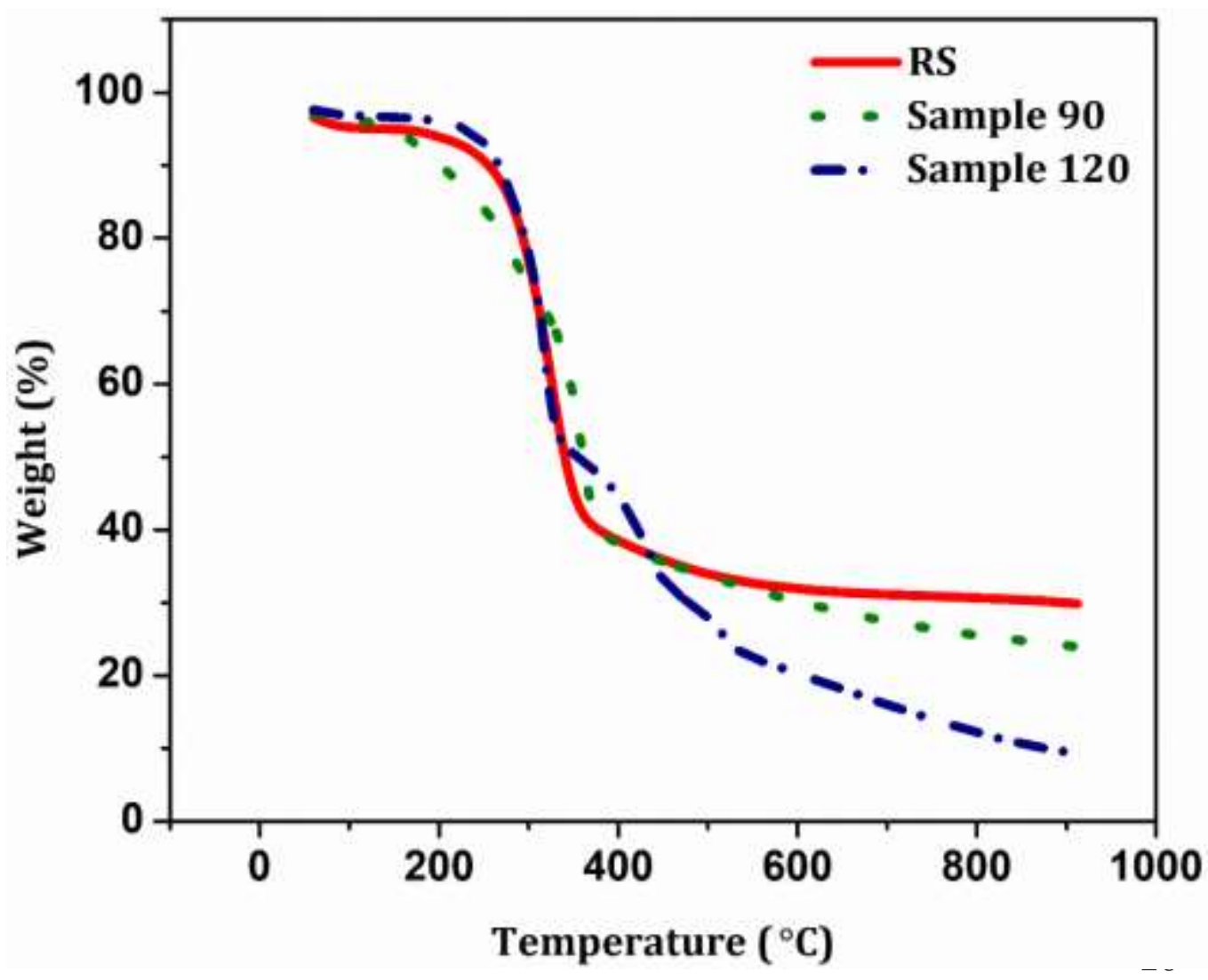

30 Figure. 5. TGA of the original RS compared with pretreated RS at $90{ }^{\circ} \mathrm{C}$ and $120{ }^{\circ} \mathrm{C}$ (RS: 31 Original Rice Straw, RS - 90: Rice Straw after heating at $90{ }^{\circ} \mathrm{C}$, RS - 120: Rice Straw after 32 heating at $120^{\circ} \mathrm{C}$ ) 
Fig. 5 suggested the pyrolysis of biomass through TGA analysis, which was significantly affected by the CrI. As displayed in Fig. 5, the decomposition temperature of hemicellulose, cellulose, and lignin is observed in the range of $220-315{ }^{\circ} \mathrm{C}, 314-400{ }^{\circ} \mathrm{C}$ and 160 to $900{ }^{\circ} \mathrm{C}$ respectively, which is the indication of generating a solid residue. The main gases could be $\mathrm{CO}_{2}, \mathrm{CO}, \mathrm{CH}_{4}$, and some organics, which are mainly responsible for the slow residence times [64]. Thus, as suggested from Fig. 5, 29\%, 21\%, and 9\% biochar was the solid carbon-rich residue left after pyrolysis of pretreated RS biomass for original RS, pretreated at 90 and 120 ${ }^{\circ} \mathrm{C}$, respectively (Fig. 5). Biochar is a low-grade fuel and can be collected in parts from all pyrolysis reactions, which can be further used as a fuel for new pyrolysis reactions. The European Bioenergy Research Institute (EBRI), Aston University runs a pyrolysis unit using biochar. Biochar has also been used as an additive to increase soil fertility and improve the water holding capacity. All these specify that the RS's waste after pretreatment can be utilized for various applications. At higher temperatures, rapid cleavage of glycosidic bonds occur leading to the formation of gaseous products both condensable and non-condensable and further pyrolysis of the pretreated RS allows the cellulose structure to degrade sharply during the initial stages of fast pyrolysis with the cleavage of more glycosidic bonds thereby leading to lesser char yields.

The TGA profile can be roughly divided into three regions. (i) $<220{ }^{\circ} \mathrm{C}$ showed weight loss (less than 10\%) which may be due to dehydration and removal of volatile components; (ii) between 220 and $360{ }^{\circ} \mathrm{C}$ showed weight loss up to $40 \%$. Between 200 and 300, the cleavage of intra- and intermolecular hydrogen bonds occurs and (iii) at $360^{\circ} \mathrm{C}$ and higher temperatures. The treated RS at $120{ }^{\circ} \mathrm{C}$ had only $9 \%$ remains of the feedstock which suggests that some chemicals were formed and waste is reduced compared to the untreated RS (29\% remains) and also RS treated at $90{ }^{\circ} \mathrm{C}$ where $21 \%$ remains. These agree with the FTIR results i.e. removal of some components.

Like petroleum cracking, many reactions occur during pyrolysis of biomass, like condensation, depolymerization, dehydration, isomerization, and charring reactions and plenty of pyrolyzed products are released [65]. Due to all the situations mentioned above, the bio-oil or gases, when trapped are not pure and have to go through another process of distillation. However, these products were not analyzed in this part of our study. Lignin pyrolysis gives mainly aromatic compounds, and pyrolysis of cellulose and hemicellulose gives aliphatic components. Due to various reactions going on simultaneously, it is a difficult task to identify the exact mechanism. 


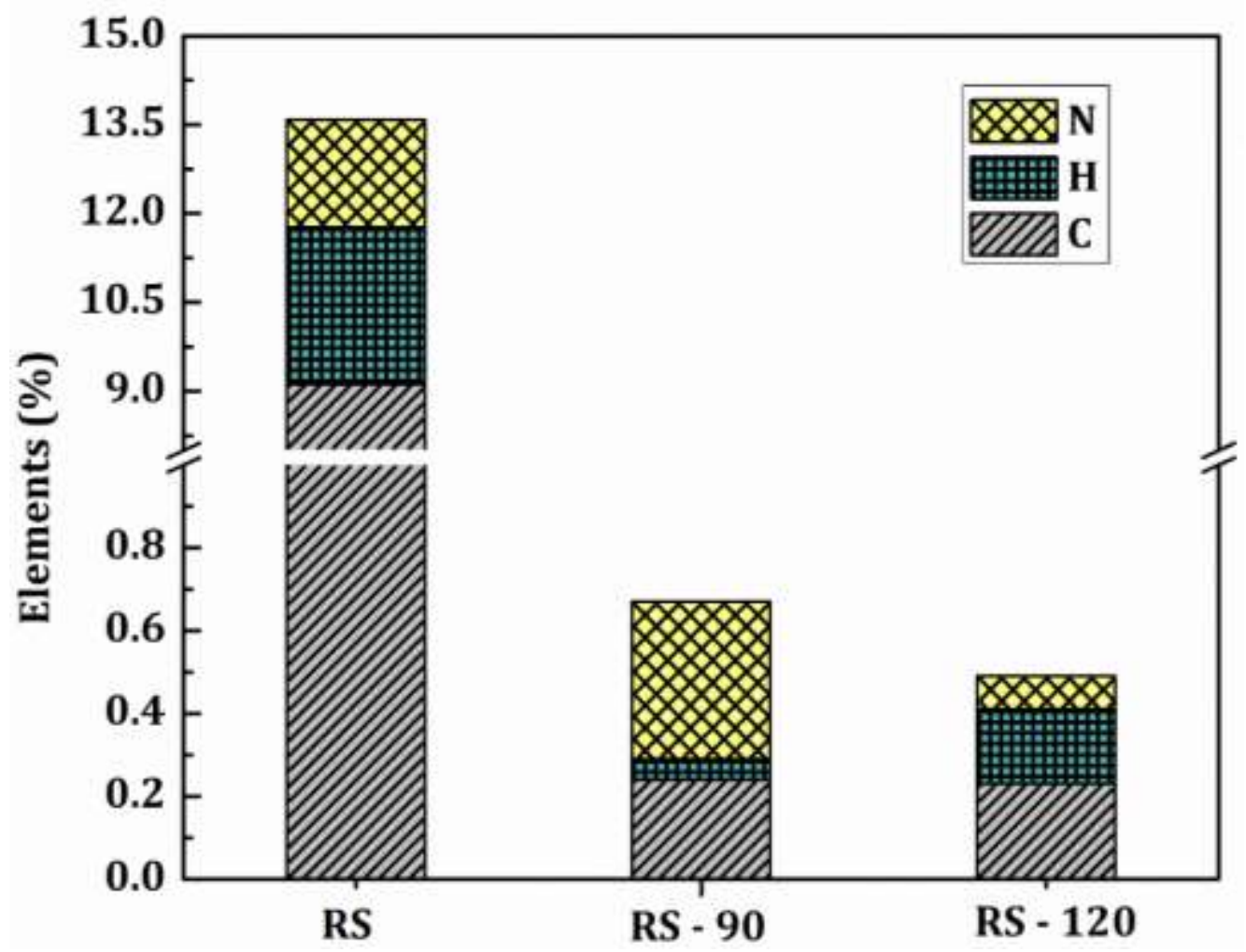

2 Figure. 6: Comparative study on the elements before and after pretreatment of rice straw (RS: 3 Original Rice Straw, RS - 90: Rice Straw after heating at $90{ }^{\circ} \mathrm{C}$, RS - 120: Rice Straw after 4 heating at $120^{\circ} \mathrm{C}$ )

5

6

Further, the changes in the CHN composition were also carried out to understand the extent of pretreatment. The original RS possessed the elements $\mathrm{C}, \mathrm{H}$, and $\mathrm{N}$ as $9.12 \%, 0.24 \%$, and $0.23 \%$, respectively. On ionothermal treatment at $90{ }^{\circ} \mathrm{C}$ and $120{ }^{\circ} \mathrm{C}$ the $\mathrm{C}, \mathrm{H}$ and $\mathrm{N}$ percentages changed to $2.65 \%, 0.05 \%, 0.38 \%$ and $1.81 \%, 0.38 \%, 0.08 \%$, respectively (Fig. 6). As the Lewis basic nature of the DBU cation enhances the $\mathrm{C}_{6}-\mathrm{O}$ bond breakage, which is mainly due to the tertiary nitrogen in the cation and helps in the dehydration of carbohydratekind polymers (Song et al. 2013). Also, the old report suggested that anion of ILs were mainly influenced the abstraction of the $\mathrm{H}$-atom. Due to this, the glycosidic bond weakens and thus the crystallinity reduces. The cellulose finally breaks into glucose, which undergoes the ionothermal condition to give HMF. This was detected using a TLC in the liquid substrate but was not analyzed quantitatively.

Next, the recyclability of IL makes it more sustainable towards biomass applications. In this regard, the recycling was carried out and the percentage of conversion as the recycling 
1 process continues is shown in Fig. 7. IL could be recycled at least 3 times for reutilization. In 2 all the cases we can see that the pretreatment at $120^{\circ} \mathrm{C}$ was more efficient. ILs were washed 3 with dichloromethane (DCM) as IL is soluble in it also. RS samples were fresh and the IL was 4 used for several cycles after washing. Up to $89 \%$ of IL was recycled three times and conversions reduced by $5 \%, 7 \%, 10 \%$ at $90{ }^{\circ} \mathrm{C}$ and $7 \%, 7 \%, 10 \%$, at $120{ }^{\circ} \mathrm{C}$. Additionally, water was used as an antisolvent to make the unwanted particles settle down easily in the vial used for experiments.

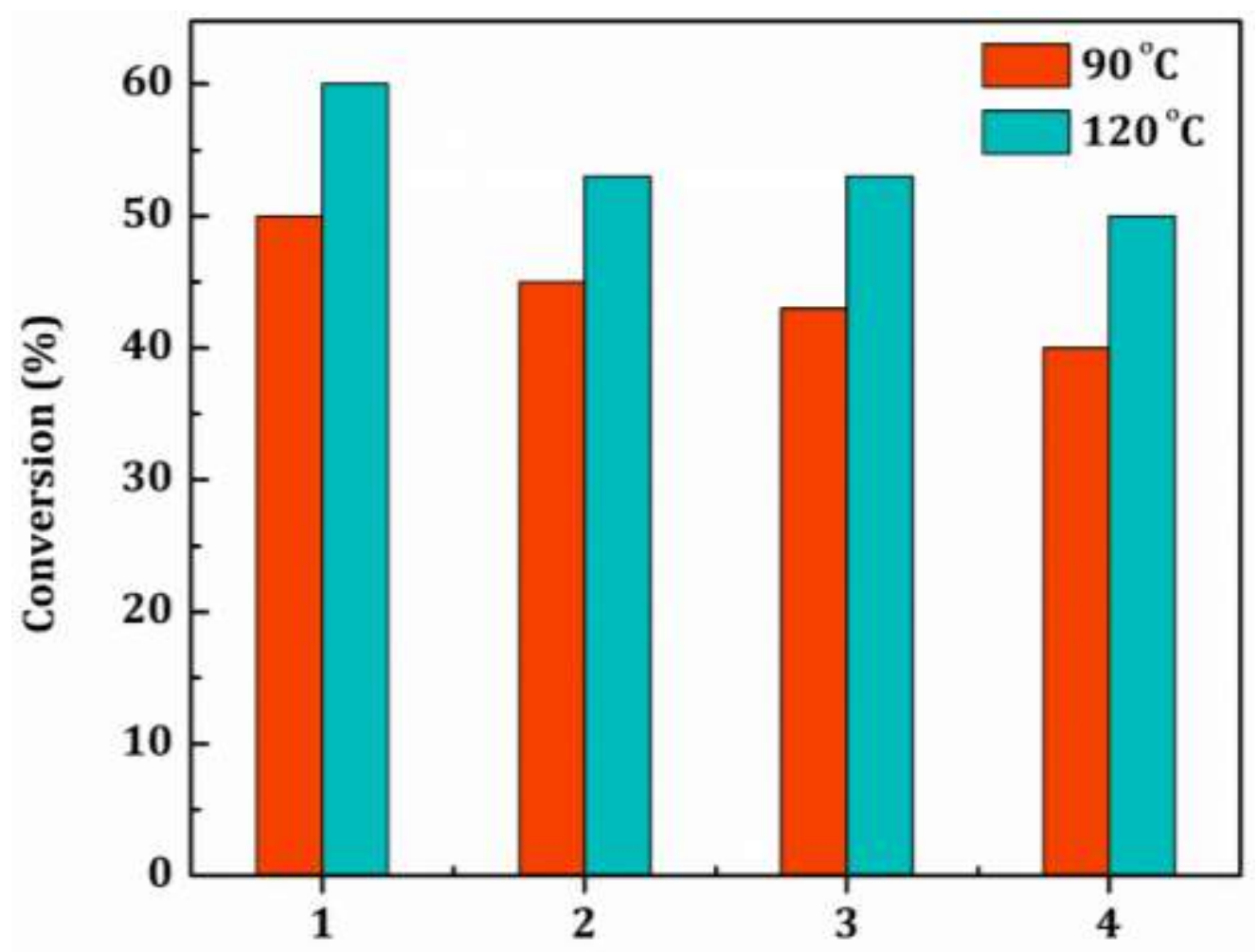

11 Fig. 7: Plot showing the effect of conversion to the reusability of [DBUH] [OTf] at different temperatures $\left(90\right.$ and $\left.120^{\circ} \mathrm{C}\right)$

So far, owing to multiple issues like the high expense behind the production of IL, large-scale uptake of ILs is impeded to some extent. Similarly, there are other factors like the detailed explanation on micro-macro as well as the molecular level of the deconstruction mechanisms which prevents the optimization and modeling, and the requirement of a technoeconomic stable assessment on large scale experiments [66]. Considering the high thermal and chemical stabilities of the studied IL, possibilities of reuse exist, which opens up an economic way of lignocellulose pretreatment in an energy-efficient method. 


\section{$14 . \quad$ Conclusions}

Ionothermal treatment alone could tear up RS into tiny fibers and cause a decrease in the crystallinity. The acetate-based ILs used in this study had less thermal stability, thereby not

4 being better solvents at higher temperatures. DBU-based IL was obtained from relatively 5 inexpensive starting material, and due to its air, water, and thermal stability and Lewis basic property of the tertiary nitrogen in the cation helped in the dehydration of carbohydrate-kind polymers.

The Lewis basic property of the tertiary nitrogen of DBU cation helped in the dehydration of carbohydrate kind polymers in $6 \mathrm{~h}$. Thus this work opens up opportunities to convert waste lignocellulosic biomass. Biochar/char yields decreased when the pretreatment was carried out at higher temperatures, and thus $120{ }^{\circ} \mathrm{C}$ had only $9 \%$ of biochar/char remains. Limited information can be obtained from TGA studies regarding the reaction intermediates, reaction pathways, etc. but useful to understand the waste management when RS was pretreated. However, the mechanism in air and nitrogen will vary. IL could be recycled at least three times pointing towards the possibility of reuse to reduce the cost issues associated with the ionic 16 liquids.

Being an attractive field of research, the journey of searching for better ILs in the pretreatment technique will continue until the research minds are satisfied with optimized reactants and reaction conditions. The idea of using ILs has to be commercialized from the narrow level of laboratory scales with suitable combinations of cheap solvents and ILs, in an economic way without harming the environmental perspectives. There are still lots of hurdles before ILs reach the biorefineries. Reusing possibilities have to be explored to achieve these goals, and pure ILs have to be substituted with their mixtures with proper solvents. Further studies in this regard as a continuation of this work will be exploring much more about the quantitative approach and IL-solvent binary mixtures for dissolution.

\section{Acknowledgments}

Authors thank Department of Chemistry, IIT Madras for PXRD, SEM, TGA, and IR facility, and SAIF, IIT Madras for CHN measurements. The authors would like to acknowledge IIT Madras for the financial support through grant number CY/20-21/069/RFIR/008452. Also thankful to Council of Scientific and Industrial Research (CSIR), India, for the financial support through Senior Research Fellowship (JRF) number 09/084(0720)/2017-EMR-I. 


\section{Conflict of interest}

The authors declare that there are no known conflicts of interest related to the content of this article. We certify that we have no financial or proprietary interests in any material discussed in this article.

\section{Supplementary Information}

Detailed descriptions on the synthesis of ILs, characterization of the ILs, the experimental procedure for the pretreatment of rice straw and crystallinity calculations are provided in the Supplementary Information (SI).

\section{References}

[1] J. Popp, Z. Lakner, M. Harangi-Rákos, M. Fári, The effect of bioenergy expansion: Food, energy, and environment, Renewable and Sustainable Energy Reviews. 32 (2014) 559-578. https://doi.org/10.1016/j.rser.2014.01.056.

[2] R.M. Dias, A.M. da Costa Lopes, A.J.D. Silvestre, J.A.P. Coutinho, M.C. da Costa, Uncovering the potentialities of protic ionic liquids based on alkanolammonium and carboxylate ions and their aqueous solutions as non-derivatizing solvents of Kraft lignin, Industrial Crops and Products. 143 (2020) 111866. https://doi.org/10.1016/j.indcrop.2019.111866.

[3] V. Dhyani, T. Bhaskar, A comprehensive review on the pyrolysis of lignocellulosic biomass, Renewable Energy. 129 (2018) 695-716. https://doi.org/10.1016/j.renene.2017.04.035.

[4] T. Kan, V. Strezov, T.J. Evans, Lignocellulosic biomass pyrolysis: A review of product properties and effects of pyrolysis parameters, Renewable and Sustainable Energy Reviews. 57 (2016) 1126-1140. https://doi.org/10.1016/j.rser.2015.12.185.

[5] Z. Hameed, S.R. Naqvi, M. Naqvi, I. Ali, S.A.A. Taqvi, N. Gao, S.A. Hussain, S. Hussain, A Comprehensive Review on Thermal Coconversion of Biomass, Sludge, Coal, and Their Blends Using Thermogravimetric Analysis, Journal of Chemistry. 2020 (2020). https://doi.org/10.1155/2020/5024369.

[6] A. Anca-Couce, C. Tsekos, S. Retschitzegger, F. Zimbardi, A. Funke, S. Banks, T. Kraia, P. Marques, R. Scharler, W. de Jong, N. Kienzl, Biomass pyrolysis TGA assessment with an international round robin, Fuel. 276 (2020) 118002. https://doi.org/10.1016/j.fuel.2020.118002.

[7] N. Dahmen, I. Lewandowski, S. Zibek, A. Weidtmann, Integrated lignocellulosic value chains in a growing bioeconomy: Status quo and perspectives, GCB Bioenergy. 11 (2019) 107-117. https://doi.org/10.1111/gcbb.12586.

[8] K.S. Baig, Interaction of enzymes with lignocellulosic materials: causes, mechanism and influencing factors, Bioresources and Bioprocessing. 7 (2020). https://doi.org/10.1186/s40643-020-00310-0.

[9] L. Machineni, Lignocellulosic biofuel production: review of alternatives, Biomass 
Conversion and Biorefinery. 10 (2020) 779-791. https://doi.org/10.1007/s13399-01900445-x.

[10] M. Gummert, N. Van Hung, P. Chivenge, B. Douthwaite, Sustainable Rice Straw Management, 2020. https://doi.org/10.1007/978-3-030-32373-8.

[11] A.M. El-Kassas, A.H. Elsheikh, A new eco-friendly mechanical technique for production of rice straw fibers for medium density fiberboards manufacturing, International Journal of Environmental Science and Technology. 18 (2021) 979-988. https://doi.org/10.1007/s13762-020-02886-8.

[12] B.A. Goodman, Utilization of waste straw and husks from rice production: A review, Journal of Bioresources and Bioproducts. 5 (2020) 143-162.

https://doi.org/10.1016/j.jobab.2020.07.001.

[13] Z. Zhang, T. Vancov, S. Mackintosh, B. Basu, A. Lali, G. Qian, P. Hobson, W.O.S. Doherty, Assessing dilute acid pretreatment of different lignocellulosic biomasses for enhanced sugar production, Cellulose. 23 (2016) 3771-3783. https://doi.org/10.1007/s10570-016-1043-6.

[14] S. Ashoor, R.K. Sukumaran, Mild alkaline pretreatment can achieve high hydrolytic and fermentation efficiencies for rice straw conversion to bioethanol, Preparative Biochemistry and Biotechnology. 50 (2020) 814-819. https://doi.org/10.1080/10826068.2020.1744007.

[15] A.K. Kumar, S. Sharma, Recent updates on different methods of pretreatment of lignocellulosic feedstocks: a review, Bioresources and Bioprocessing. 4 (2017) 1-19. https://doi.org/10.1186/s40643-017-0137-9.

[16] Y.L. Loow, T.Y. Wu, G.H. Yang, J. Md. Jahim, W.H. Teoh, A.W. Mohammad, Role of energy irradiation in aiding pretreatment of lignocellulosic biomass for improving reducing sugar recovery, Cellulose. 23 (2016) 2761-2789. https://doi.org/10.1007/s10570-016-1023-x.

[17] T.A. Shah, C.C. Lee, W.J. Orts, R. Tabassum, Biological pretreatment of rice straw by ligninolytic Bacillus sp. strains for enhancing biogas production, Environmental Progress and Sustainable Energy. 38 (2019) 1-9. https://doi.org/10.1002/ep.13036.

[18] S.K. Bhatia, S.S. Jagtap, A.A. Bedekar, R.K. Bhatia, A.K. Patel, D. Pant, J. Rajesh Banu, C. V. Rao, Y.G. Kim, Y.H. Yang, Recent developments in pretreatment technologies on lignocellulosic biomass: Effect of key parameters, technological improvements, and challenges, Bioresource Technology. 300 (2020) 122724. https://doi.org/10.1016/j.biortech.2019.122724.

[19] N. Sathitsuksanoh, Z. Zhu, Y.H.P. Zhang, Cellulose solvent-based pretreatment for corn stover and avicel: Concentrated phosphoric acid versus ionic liquid [BMIM]Cl, Cellulose. 19 (2012) 1161-1172. https://doi.org/10.1007/s10570-012-9719-z.

[20] S. Yang, X. Lu, Y. Zhang, J. Xu, J. Xin, S. Zhang, Separation and characterization of cellulose I material from corn straw by low-cost polyhydric protic ionic liquids, Cellulose. 25 (2018) 3241-3254. https://doi.org/10.1007/s10570-018-1785-4.

[21] D. Singh, G. Sharma, R.L. Gardas, Better Than the Best Polar Solvent: Tuning the Polarity of 1,2,4- Triazolium-Based Ionic Liquids, ChemistrySelect. 2 (2017) 39433947. https://doi.org/10.1002/slct.201700639.

[22] G. Sharma, R.L. Gardas, A. Coronas, G. Venkatarathnam, Effect of anion chain length 
on physicochemical properties of N,N-dimethylethanolammonium based protic ionic liquids, Fluid Phase Equilibria. 415 (2016) 1-7. https://doi.org/10.1016/j.fluid.2016.01.036.

[23] A. Sarkar, G. Sharma, D. Singh, R.L. Gardas, Effect of anion on thermophysical properties of N,N-diethanolammonium based protic ionic liquids, Journal of Molecular Liquids. 242 (2017) 249-254. https://doi.org/10.1016/j.molliq.2017.07.025.

[24] A.O. Diallo, G. Fayet, C. Len, G. Marlair, Evaluation of heats of combustion of ionic liquids through use of existing and purpose-built models, Industrial and Engineering Chemistry Research. 51 (2012) 3149-3156. https://doi.org/10.1021/ie2023788.

[25] H. Liu, E. Maginn, A.E. Visser, N.J. Bridges, E.B. Fox, Thermal and transport properties of six ionic liquids: An experimental and molecular dynamics study, Industrial and Engineering Chemistry Research. 51 (2012) 7242-7254. https://doi.org/10.1021/ie300222a.

[26] A. Mukhopadhayay, D. Singh, K.P. Sharma, Neat Ionic liquid and $\alpha$-ChymotrypsinPolymer Surfactant Conjugate-Based Biocatalytic Solvent, Biomacromolecules. 21 (2020) 867-877. https://doi.org/10.1021/acs.biomac.9b01556.

[27] A.S. Rodriguez Castillo, S. Guihéneuf, P.F. Biard, L. Paquin, A. Amrane, A. Couvert, Physicochemical properties of some hydrophobic room-temperature ionic liquids applied to volatile organic compounds biodegradation processes, Journal of Chemical Technology and Biotechnology. 93 (2018) 215-223. https://doi.org/10.1002/jctb.5343.

[28] W.M. Nelson, Are Ionic Liquids Green Solvents?, ACS Symposium Series. 818 (2002) 30-41. https://doi.org/10.1021/bk-2002-0818.ch003.

[29] Z. Usmani, M. Sharma, P. Gupta, Y. Karpichev, N. Gathergood, R. Bhat, V.K. Gupta, Ionic liquid based pretreatment of lignocellulosic biomass for enhanced bioconversion, Bioresource Technology. 304 (2020) 123003. https://doi.org/10.1016/j.biortech.2020.123003.

[30] K. Rajan, T. Elder, N. Abdoulmoumine, D.J. Carrier, N. Labbé, Correction: Understanding the in situ state of lignocellulosic biomass during ionic liquids-based engineering of renewable materials and chemicals , Green Chemistry. (2021) 37996. https://doi.org/10.1039/d1gc90089g.

[31] L. Liang, J. Yan, Q. He, T. Luong, T.R. Pray, B.A. Simmons, N. Sun, Scale-up of biomass conversion using 1-ethyl-3-methylimidazolium acetate as the solvent, Green Energy and Environment. 4 (2019) 432-438. https://doi.org/10.1016/j.gee.2018.07.002.

[32] L. Mesa, V.S. Valerio, M.B. Soares Forte, J.C. Santos, E. González, S.S. da Silva, Optimization of $\mathrm{BmimCl}$ pretreatment of sugarcane bagasse through combining multiple responses to increase sugar production. An approach of the kinetic model, Biomass Conversion and Biorefinery. (2020). https://doi.org/10.1007/s13399-02000792-0.

[33] S. Naz, M. Uroos, A.M. Asim, N. Muhammad, F.U. Shah, One-Pot Deconstruction and Conversion of Lignocellulose Into Reducing Sugars by Pyridinium-Based Ionic Liquid-Metal Salt System, Frontiers in Chemistry. 8 (2020) 1-11. https://doi.org/10.3389/fchem.2020.00236.

[34] P. Moyer, K. Kim, N. Abdoulmoumine, S.C. Chmely, B.K. Long, D.J. Carrier, N. 
Labbé, Structural changes in lignocellulosic biomass during activation with ionic liquids comprising 3-methylimidazolium cations and carboxylate anions 03 Chemical Sciences 0306 Physical Chemistry (incl. Structural), Biotechnology for Biofuels. 11 (2018) 1-13. https://doi.org/10.1186/s13068-018-1263-0.

[35] B. Zhao, L. Greiner, W. Leitner, Cellulose solubilities in carboxylate-based ionic liquids, RSC Advances. 2 (2012) 2476-2479. https://doi.org/10.1039/c2ra01224c.

[36] W. Zhang, J. Liu, Y. Wang, J. Sun, P. Huang, K. Chang, Effect of ultrasound on ionic liquid-hydrochloric acid pretreatment with rice straw, Biomass Conversion and Biorefinery. 11 (2021) 1749-1757. https://doi.org/10.1007/s13399-019-00595-y.

[37] A. Abdolmaleki, S.S. Nabavizadeh, M. Badbedast, 1-(Carboxymethyl)pyridinium chloride as an acidic ionic liquid for rice straw effective pretreatment, Renewable Energy. 177 (2021) 544-553. https://doi.org/10.1016/j.renene.2021.05.158.

[38] X.D. Hou, T.J. Smith, N. Li, M.H. Zong, Novel renewable ionic liquids as highly effective solvents for pretreatment of rice straw biomass by selective removal of lignin, Biotechnology and Bioengineering. 109 (2012) 2484-2493. https://doi.org/10.1002/bit.24522.

[39] G. Gogoi, S. Hazarika, Coupling of ionic liquid treatment and membrane filtration for recovery of lignin from lignocellulosic biomass, Separation and Purification Technology. 173 (2017) 113-120. https://doi.org/10.1016/j.seppur.2016.09.019.

[40] K.H. Kim, T. Dutta, J. Sun, B. Simmons, S. Singh, Biomass pretreatment using deep eutectic solvents from lignin derived phenols, Green Chemistry. 20 (2018) 809-815. https://doi.org/10.1039/c7gc03029k.

[41] Y.W. Sai, K.M. Lee, Enhanced cellulase accessibility using acid-based deep eutectic solvent in pretreatment of empty fruit bunches, Cellulose. 26 (2019) 9517-9528. https://doi.org/10.1007/s10570-019-02770-w.

[42] S.P. Magalhães Da Silva, A.M. Da Costa Lopes, L.B. Roseiro, R. Bogel-Łukasik, Novel pre-treatment and fractionation method for lignocellulosic biomass using ionic liquids, RSC Advances. 3 (2013) 16040-16050. https://doi.org/10.1039/c3ra43091j.

[43] K. Dong, S. Zhang, J. Wang, Understanding the hydrogen bonds in ionic liquids and their roles in properties and reactions, Chemical Communications. 52 (2016) 67446764. https://doi.org/10.1039/c5cc10120d.

[44] T.A. Bioni, M.L. de Oliveira, M.T. Dignani, O.A. El Seoud, Understanding the efficiency of ionic liquids-DMSO as solvents for carbohydrates: use of solvatochromic- And related physicochemical properties, New Journal of Chemistry. 44 (2020) 14906-14914. https://doi.org/10.1039/d0nj02258f.

[45] I. Persson, Solvation and complex formation in strongly solvating solvents, Pure and Applied Chemistry. 58 (1986) 1153-1161. https://doi.org/10.1351/pac198658081153.

[46] A. Brandt, J. Gräsvik, J.P. Hallett, T. Welton, Deconstruction of lignocellulosic biomass with ionic liquids, Green Chemistry. 15 (2013) 550-583. https://doi.org/10.1039/c2gc36364j.

[47] G. Sharma, Y. Kato, A. Hachisu, K. Ishibashi, K. Ninomiya, K. Takahashi, E. Hirata, K. Kuroda, Synthesis of a cellulose dissolving liquid zwitterion from general and lowcost reagents, Cellulose. 0123456789 (2021). https://doi.org/10.1007/s10570-02104185-y. 
[48] P. Weerachanchai, J.M. Lee, Recyclability of an ionic liquid for biomass pretreatment, Bioresource Technology. 169 (2014) 336-343. https://doi.org/10.1016/j.biortech.2014.06.072.

[49] J.N. Pedersen, B. Pérez, Z. Guo, Stability of cellulase in ionic liquids: correlations between enzyme activity and COSMO-RS descriptors, Scientific Reports. 9 (2019) 111. https://doi.org/10.1038/s41598-019-53523-5.

[50] K.J. Jisha, D. Singh, G. Sharma, R.L. Gardas, Effect of temperature on apparent molar properties of DBU based protic ionic liquid in aqueous and ethanolic solutions, Journal of Molecular Liquids. 231 (2017) 213-219. https://doi.org/10.1016/j.molliq.2017.02.006.

[51] D. Singh, R.L. Gardas, Influence of Cation Size on the Ionicity, Fluidity, and Physiochemical Properties of 1,2,4-Triazolium Based Ionic Liquids, Journal of Physical Chemistry B. 120 (2016) 4834-4842. https://doi.org/10.1021/acs.jpcb.6b03669.

[52] G. Sharma, D. Singh, S. Rajamani, R.L. Gardas, Influence of Alkyl Substituent on Optical Properties of Carboxylate-Based Protic Ionic Liquids, ChemistrySelect. 2 (2017). https://doi.org/10.1002/slct.201701878.

[53] C.L. Chambon, T.Y. Mkhize, P. Reddy, A. Brandt-Talbot, N. Deenadayalu, P.S. Fennell, J.P. Hallett, Pretreatment of south african sugarcane bagasse using a low-cost protic ionic liquid: A comparison of whole, depithed, fibrous and pith bagasse fractions, Biotechnology for Biofuels. 11 (2018) 1-16. https://doi.org/10.1186/s13068018-1247-0.

[54] M. Thakur, A. Sharma, V. Ahlawat, M. Bhattacharya, S. Goswami, Process optimization for the production of cellulose nanocrystals from rice straw derived $\alpha$ cellulose, Materials Science for Energy Technologies. 3 (2020) 328-334. https://doi.org/10.1016/j.mset.2019.12.005.

[55] A.D. French, Increment in evolution of cellulose crystallinity analysis, Cellulose. 27 (2020) 5445-5448. https://doi.org/10.1007/s10570-020-03172-z.

[56] P. Ahvenainen, I. Kontro, K. Svedström, Comparison of sample crystallinity determination methods by X-ray diffraction for challenging cellulose I materials, Cellulose. 23 (2016) 1073-1086. https://doi.org/10.1007/s10570-016-0881-6.

[57] M. Wojdyr, Fityk: A general-purpose peak fitting program, Journal of Applied Crystallography. 43 (2010) 1126-1128. https://doi.org/10.1107/S0021889810030499.

[58] W. Yao, Y. Weng, J.M. Catchmark, Improved cellulose X-ray diffraction analysis using Fourier series modeling, Cellulose. 27 (2020) 5563-5579. https://doi.org/10.1007/s10570-020-03177-8.

[59] D.R. del Cerro, T. V. Koso, T. Kakko, A.W.T. King, I. Kilpeläinen, Crystallinity reduction and enhancement in the chemical reactivity of cellulose by non-dissolving pre-treatment with tetrabutylphosphonium acetate, Cellulose. 27 (2020) 5545-5562. https://doi.org/10.1007/s10570-020-03044-6.

[60] P. Bhaumik, P.L. Dhepe, Conversion of biomass into sugars, 2016. https://doi.org/10.1039/9781782622079-00001.

[61] M. Yang, X.R. Song, P.F. Deng, H.R. Yang, Pyrolysis and liquefaction of biomass, Linchan Huaxue Yu Gongye/Chemistry and Industry of Forest Products. 20 (2000) 
77-82.

[62] F.C. De Melo, R.F. De Souza, P.L.A. Coutinhob, M.O. De Souza, Synthesis of 5Hydroxymethylfurfural from dehydration of fructose and glucose using ionic liquids, Journal of the Brazilian Chemical Society. 25 (2014) 2378-2384. https://doi.org/10.5935/0103-5053.20140256.

[63] L. Feng, Z. Chen, Research progress on dissolution and functional modi fi cation of cellulose in ionic liquids, 142 (2008) $1-5$. https://doi.org/10.1016/j.molliq.2008.06.007.

[64] H. Yang, Characteristics of hemicellulose , cellulose and lignin pyrolysis, 86 (2007) 1781-1788. https://doi.org/10.1016/j.fuel.2006.12.013.

[65] Q. Wang, X. Zhang, S. Sun, Z. Wang, D. Cui, Effect of CaO on Pyrolysis Products and Reaction Mechanisms of a Corn Stover, ACS Omega. 5 (2020) 10276-10287. https://doi.org/10.1021/acsomega.9b03945.

[66] P. Halder, S. Kundu, S. Patel, A. Setiawan, R. Atkin, R. Parthasarthy, J. Paz-Ferreiro, A. Surapaneni, K. Shah, Progress on the pre-treatment of lignocellulosic biomass employing ionic liquids, Renewable and Sustainable Energy Reviews. 105 (2019) 268292. https://doi.org/10.1016/j.rser.2019.01.052. 
2 Graphical Abstract

3

4

5

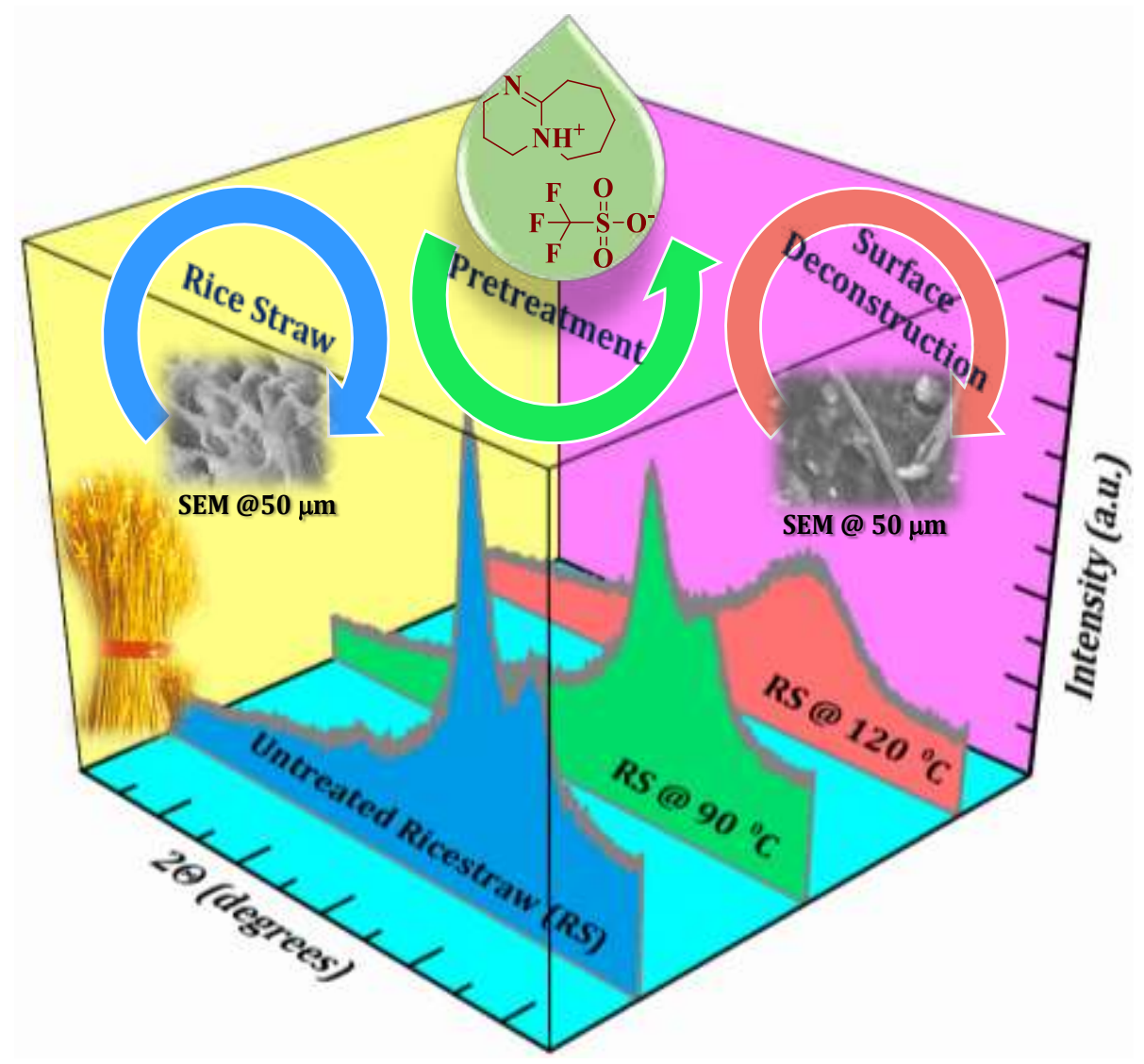

